\title{
The Influence of Different Types of Nanofluid on Thermal and Fluid Flow Performance of Liquid Cold Plate
}

\author{
Nur Irmawati Om ${ }^{* 1}$, Rozli Zulkifli², P. Gunnasegaran ${ }^{3}$ \\ ${ }^{1,2}$ Department of Mechanical and Materials Engineering, Universiti Kebangsaan Malaysia, Bangi 43600, Selangor, Malaysia \\ ${ }^{3}$ Institute of Power Engineering, Universiti Tenaga Nasional, Km 7, 43000 Kajang, Selangor, Malaysia \\ *Corresponding author E-mail: Irmawati@ uniten.edu.my
}

\begin{abstract}
The influence of utilizing different nanofluids types on the liquid cold plate (LCP) is numerically investigated. The thermal and fluid flow performance of LCP is examined by using pure ethylene glycol (EG), $\mathrm{Al}_{2} \mathrm{O}_{3}$-EG and CuO-EG. The volume fraction of the nanoparticle for both nanofluid is $2 \%$. The finite volume method (FVM) has been used to solved 3-D steady state, laminar flow and heat transfer governing equations. The presented results indicate that $\mathrm{Al}_{2} \mathrm{O}_{3}-\mathrm{EG}$ able to provide the lowest surface temperature of the heater block followed by $\mathrm{CuO}-\mathrm{EG}$ and $\mathrm{EG}$, respectively. It is also found that the pressure drop and friction factor are higher for $\mathrm{Al}_{2} \mathrm{O}_{3}-\mathrm{EG}$ and $\mathrm{CuO}-$ EG compared to the pure EG.
\end{abstract}

Keywords: heat transfer; liquid cold plate; nanofluids

\section{Introduction}

There is a crucial need of a better thermal management cooling system to deals with the rapid demand of batteries for electric vehicles (EV). Lithium-ion batteries are commonly used for electric vehicle because of its low self-discharge rate, long life cycle and high density [1]. A reliable thermal management cooling system is essential to allow the batteries to operate at the permitted operating temperature. Using liquid cold plate (LCP) system would be the best choice as liquid has the highest thermal conductivity. Ethylene glycol (EG) and engine oil are the conventional coolant that have been used for the battery thermal management system. The cells of the battery can be cooled using oil, air or a water-ethylene glycol mix. A study by Kim and Pesaran [2] proves that mixture of water-ethylene glycol is better than oil.

The thermal management of cold plate with serpentine channel shaped was studied by Tao et al. [3]. They numerically investigated the effect of layout and number of the serpentine channel and coolant's inlet temperature to the thermal enhancement of the cold plate. The result shows that the cooling rate was enhanced for the cold plate which contains 5 channels. They also found that the cooling temperature was rises as the coolant's inlet temperature increases.

Panchal et. al [4] performed an experimental and numerical investigation of mini-channel liquid cold plates for prismatic EV battery. They observed that by increase the temperature of minichannel cold plate able to enhanced the rate of discharge and operating temperature.

Huo et al. [5] studied the thermal management system of LCP with mini-channel for EV battery. They investigated the effect of number of channel, flow direction, inlet mass flow rate and ambient temperature. They found that the temperature of the battery was dropped when the inlet mass flow rate and number of channel were higher. They also concluded that flow direction contributes slightly impact to the cooling performance for the case with high mass flow rate.

Over the last several decades, many scientists and researchers have attempted to develop fluids that provide better cooling performance for a variety of thermal management system. Recently, nanofluids-technology came into the vogue as an advanced technology where has an ability to improve the heat transfer performance compared to conventional fluids. Nanofluids is known as a mixture of nanometer-sized particles such as metals or oxides that mixing in a base fluid. The existence of nanoparticles could enhance the nanofluids's thermal conductivity.

Huo and Zhou [6] performed numerical study by adding the nanoparticle of $\mathrm{Al}_{2} \mathrm{O}_{3}$ to the base fluid of water as the coolant of liquid cooling system. They found that battery mean temperature decreased by $7 \%$ by utilizing $\mathrm{Al}_{2} \mathrm{O}_{3}-\mathrm{H}_{2} \mathrm{O}$ nanofluids with 0.04 volume concentration compared to the pure water.

Lee et. al [7] performed experimental investigation to observed the thermal conductivity of water and EG enhancement by using nanoparticle of $\mathrm{Al}_{2} \mathrm{O}_{3}$ and $\mathrm{CuO}$. They concluded that the shape and size of the nanoparticle were influenced the enhancement percentage of the thermal conductivity.

From above literature review, there has been few studies that focused on the thermal and fluid flow characteristics of LCP utilizing nanofluid. There is no previous study has addressed the thermal and fluid flow performance of LCP using nanofluid as a coolant and this driven the current study. Hence, this study deals with 3-D numerical simulations through LCP utilizing EG, $\mathrm{Al}_{2} \mathrm{O}_{3}$-EG and $\mathrm{CuO}-\mathrm{EG}$ with nanoparticle's volume concentration of $2 \%$ for Reynolds number ranged from 200-1000. The surface temperature, Nusselt number, heat transfer rate, friction factor and pressure drop are presented in this paper. 


\section{Physical Model}

Fig. 1 shows the exploded view of the LCP system of the battery. The LCP is sandwiched by the two battery packs. The LCP is made of copper and the battery pack is made by aluminium. The battery pack is rectangular in shape with a size of $180 \mathrm{~mm}$ width and $360 \mathrm{~mm}$ length. Heat is supplied to the top and bottom to the both of battery packs. The thickness of the battery pack is $32 \mathrm{~mm}$ while the thickness of the LCP is designed to be $16 \mathrm{~mm}$. Two channels for inlet and outlet of the coolant are distributed on the side of the LCP. The LCP contains two parts which are top plate and bottom plate. The top plate is designed as a cover to the bottom plate while the bottom plate is the part which contains the oblique fin. There is middle divider inside the LCP and to reduce the pressure loss, all the corners are designed to be rounded. The configuration of the oblique fin inside the LCP is shown in Fig. 2. Fig. 3(a) and (b) display the dimension of the LCP and battery pack, respectively. In current study, the influence of nanofluids in the LCP system on the thermal and fluid flow performance are considered.

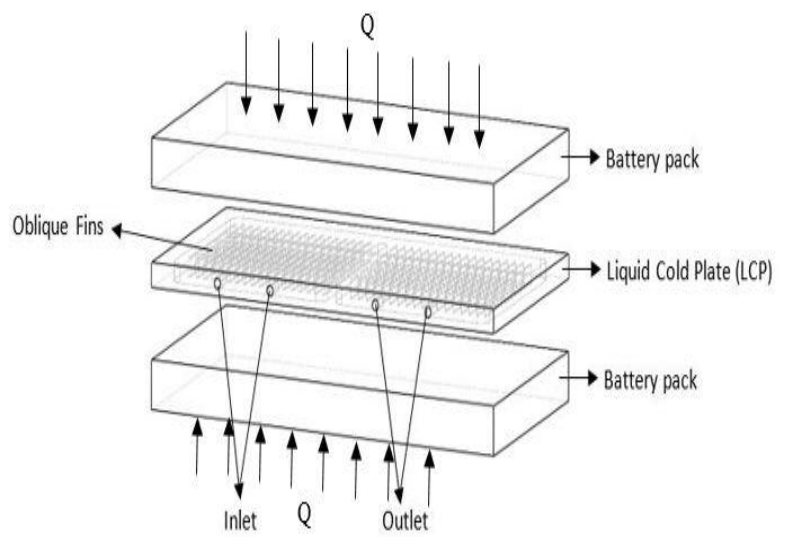

Fig. 1: Exploded view of the LCP cooling system of the battery

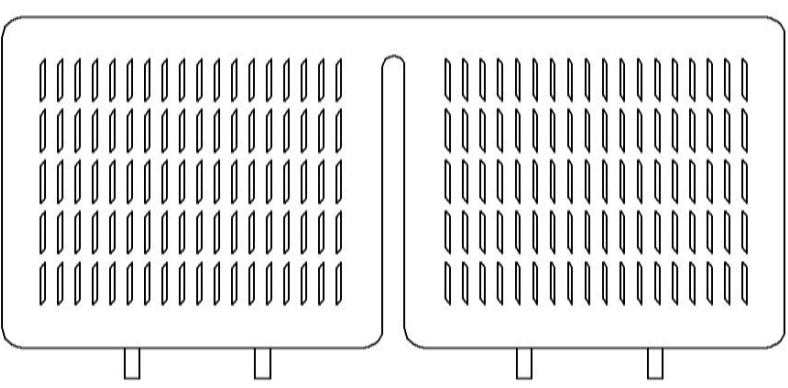

Fig. 2: Configuration of the oblique fin inside the LCP

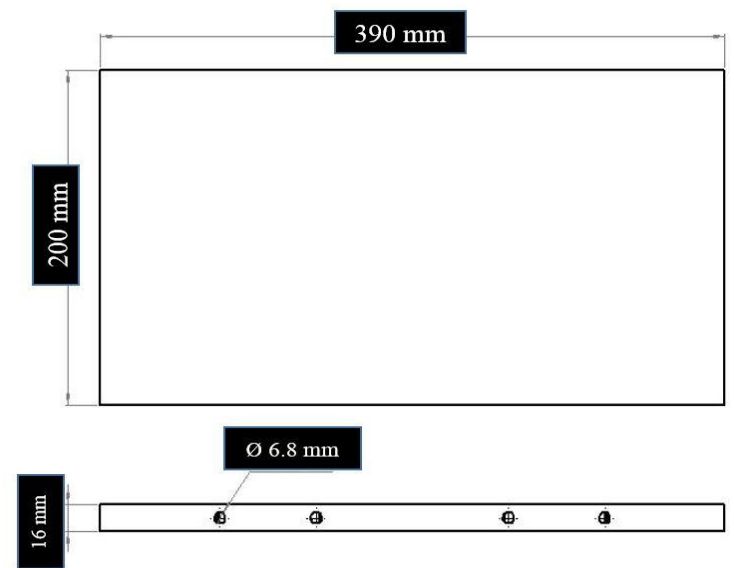

(a)

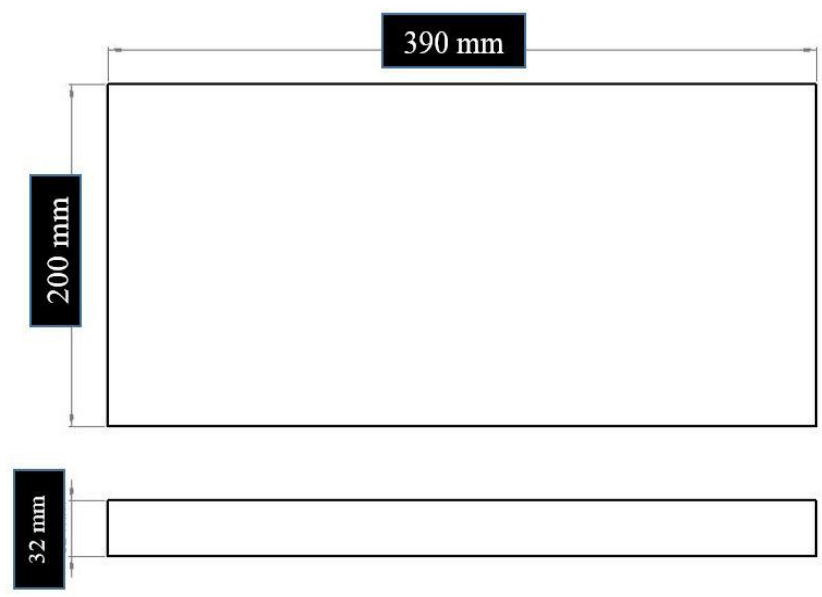

(b)

Fig. 3: Dimension of (a) LCP (b) Battery pack

The Navier-Stokes and energy equations to investigate the effect of nanofluids on the heat transfer and fluid flow characteristics is solved by employed following assumptions accordingly; (i) steady state (ii) laminar flow (iii) incompressible fluid.

The governing equations for the physical problem in the present study listed as folowing:

Continuity equation:

$\frac{\partial \rho_{f}}{\partial t}+\nabla \cdot\left(\rho_{f} \vec{v}\right)=0$

Momentum conservation equation:

$\frac{\partial}{\partial t}\left(\rho_{f} \vec{v}\right)+\nabla \cdot\left(\rho_{f} \vec{v} \vec{v}\right)=-\nabla P$

Energy conservation equation:

$\frac{\partial}{\partial t}\left(\rho_{f} C_{p f} T_{f}\right)+\nabla \bullet\left(\rho_{f} C_{p f} \vec{v} T_{f}\right)=\nabla \bullet\left(k_{f} \nabla T_{f}\right)$

The thermophysical properties of nanofluids as listed in Table 1 are calculated by using following equations [8]:

The dynamic viscosity:

$\mu_{n f}=\mu_{b f}(1+2.5 \varphi)$

The thermal conductivity:

$\frac{k_{n f}}{k_{b f}}=\frac{k_{p}+2 k_{b f}+2\left(k_{p}-k_{b f}\right) \varphi}{k_{p}+2 k_{b f}-2\left(k_{p}-k_{b f}\right) \varphi}$

The density:

$\rho_{n f}=(1-\varphi) \rho_{b f}+\varphi \rho_{p}$

The heat capacitance:

$\left(\rho C_{p}\right)_{n f}=(1-\varphi)\left(\rho C_{p}\right)_{b f}+\varphi\left(\rho C_{p}\right)_{p}$

The coefficient of thermal expansion:

$(\rho \beta)_{n f}=\varphi_{p} \rho_{p} \beta_{p}+(1-\varphi) \rho_{f} \beta_{f}$ 
where ' $p$ ' represents nanoparticle, ' $b f$ ' represents base fluids and ' $n f$ ' represents nanofluids

Table 1: The thermophysical properties of EG and nanofluids at volume fraction of $2 \%$.

\begin{tabular}{|c|c|c|c|}
\hline Properties & Base fluid $(\mathrm{EG})$ & $\mathrm{Al}_{2} \mathrm{O}_{3}$-EG & CuO-EG \\
\hline$\rho\left(\mathrm{kg} / \mathrm{m}^{3}\right)$ & 1132 & 1188.76 & 1239.36 \\
\hline $\mathrm{C}_{\mathrm{p}}(\mathrm{J} / \mathrm{kg} . \mathrm{K})$ & 2349 & 2243.20 & 2158.79 \\
\hline $\mathrm{k}(\mathrm{W} / \mathrm{m} . \mathrm{K})$ & 0.258 & 0.273 & 0.273 \\
\hline$\mu\left(\mathrm{Ns} / \mathrm{m}^{2}\right)$ & 0.0151 & 0.0184 & 0.0184 \\
\hline$\beta(1 / \mathrm{K})$ & 0.00049 & 0.00048 & 0.00043 \\
\hline
\end{tabular}

\section{Numerical Method}

In the present study, the numerical simulation is performed using ANSYS FLUENT software. The meshed of full domain computational model of LCP with top and bottom heater block which react as battery pack is depicted in Fig. 4. The LCP and both heater blocks are meshed with tetrahedral mesh scheme and 250,000 tetrahedral cells are generated in the entire 3D computational domain.

As the mesh file is exported to FLUENT, the double precision pressure based solver is selected with standard SIMPLE algorithm as its pressure-velocity coupling method. Second order upwind discretization is selected for pressure and momentum equation. The material selection for both heater block is aluminium with thermal conductivity of $202.4 \mathrm{~W} / \mathrm{m} \mathrm{K}$ while copper with thermal conductivity of $387.6 \mathrm{~W} / \mathrm{m} \mathrm{K}$ is modeled as the fins and LCP material. The inlet velocity of the working fluid is uniform and the inlet temperature of the working fluid is $27^{\circ} \mathrm{C}$. Outlet pressure is set with a gauge pressure of $0 \mathrm{~Pa}$. A constant heat flux of $300 \mathrm{~W}$ is applied evenly at the upper and bottom surface of the both heater blocks.

The Nusselt number is obtained using the following equation [9]:

$N u=\frac{h D_{h}}{k_{f}}$

where $D_{h}$ is LCP's hydraulic diameter, $k_{f}$ is the fluid's thermal conductivity and $h$ is heat transfer coefficient where calculated using following equation [10]:

$$
h=\frac{Q}{T_{s}-\frac{T_{\text {in }}+T_{\text {out }}}{2}}
$$

where $Q$ is heat flux applied, $T_{s}$ is the surface temperature of the battery, $T_{\text {in }}$ is inlet temperature and $T_{\text {out }}$ is outlet temperature. The pressure drop is obtained using equatio [11]:

$\Delta P=p_{\text {in }}-p_{\text {out }}$

where $p_{\text {in }}$ is the inlet pressure of LCP and $p_{\text {out }}$ is the outlet pressure of the LCP.

The friction factor is obtained by using following equation [12]:

$f=\frac{D_{h}}{4 L} \frac{\Delta P}{0.5 \rho u^{2}}$

where $L$ is oblique fin's length, $\rho$ is fluid's density and $u$ is fluid's inlet velocity.

Tetrahedral grid element is used in the present simulation. The grid distribution on the LCP and heater blocks is set to be uniform while at the inlet and interface wall between LCP and heater blocks the grid is set to be non-uniform. An extensive mesh testing is performed by selecting three different grid sizes of 0.005 , 0.004 and 0.003 to carry out the grid independent test and the grid size of 0.003 is ensures the grid independent solution. Hence, the current results are performed on a grid size of 0.003 . The ascertain the validity of the present numerical solution, the case of heat transfer in minichannel LCP is compared with Rashdan [13] as depicted in Fig. 5. As shown in Fig. 5, the result of present numerical study and the previous experimental study have the acceptable. agreement.

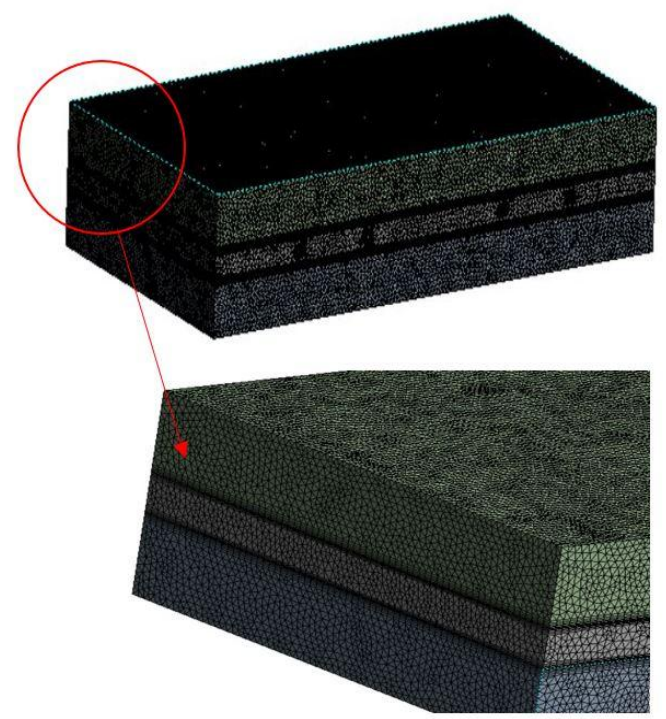

Fig. 4: The meshed of full domain computational model

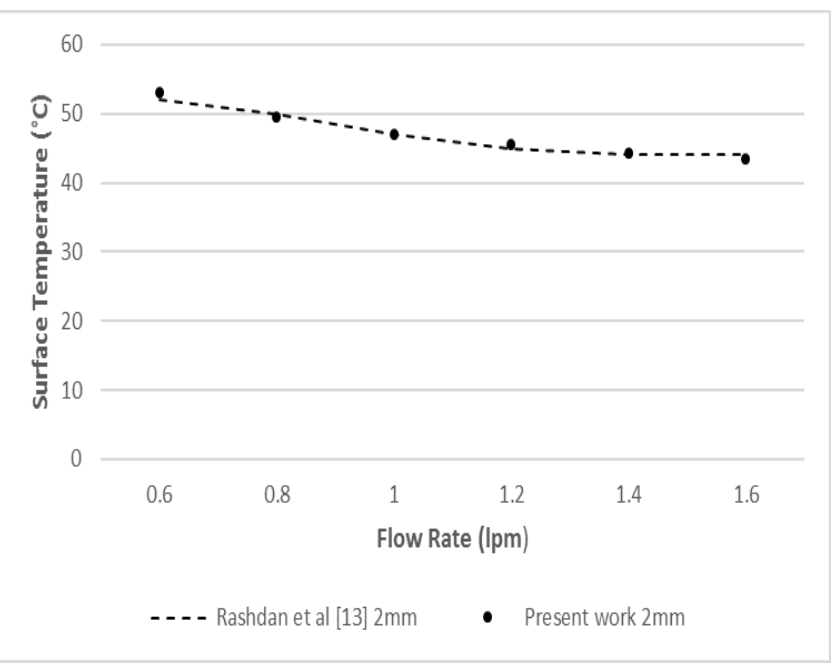

Fig. 5: Validation results

\section{Results and Discussions}

Pure EG and two types of nanofluids namely $\mathrm{Al}_{2} \mathrm{O}_{3}-\mathrm{EG}$ and $\mathrm{CuO}$ EG are considered in this study. The volume fraction for both nanoparticles is set to be $2 \%$ and the range of Reynolds number used is $200 \leq \operatorname{Re} \leq 1000$.

\subsection{Surface Temperature}

The surface temperature of the heater block is depicted in Fig. 6. It has been observed that the highest surface temperature of the heater block is obtained by utilizing pure EG. As clearly seen from Fig 6, $\mathrm{Al}_{2} \mathrm{O}_{3}$-EG has the lowest surface temperature of heater block followed by $\mathrm{CuO}-\mathrm{EG}$. This is shows that the existence of nanoparticle in the EG could greatly improve the cooling performance of LCP system. Furthermore, it is reported that the surface temperature of heater block is drops with increasing of Reynolds number 
for all cases. This may be due to the forced convection is being main feature during the process of heat transfer inside the LCP. Nevertheless, for all cases, the surface temperature of heater block at the lowest Reynolds number of 200 surpassing the allowable working temperature of $50^{\circ} \mathrm{C}$ hence it is inappropriate Reynolds number (flow rate) for battery cooling system. The lowest surface temperature of $42.47^{\circ} \mathrm{C}$ is achieved at a Reynolds number of 1000 by utilizing $\mathrm{Al}_{2} \mathrm{O}_{3}$-EG.

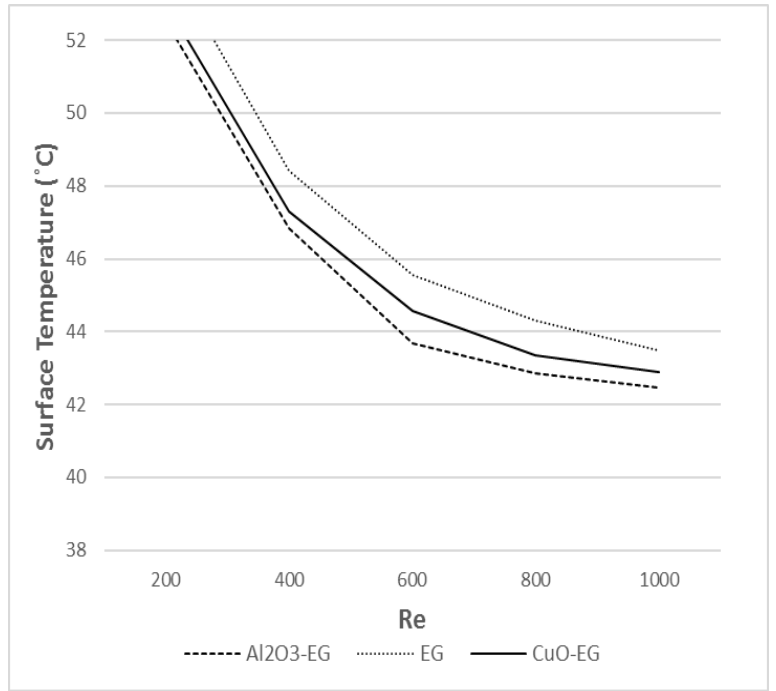

Fig. 6: Surface temperature for EG and various nanofluids

\subsection{Nusselt Number}

The thermal performance of the LCP system is observed by plotting the result of Nusselt number inside the LCP as shown in Fig. 7. It is found that $\mathrm{Al}_{2} \mathrm{O}_{3}$-EG and $\mathrm{CuO}-\mathrm{EG}$ have a capability to improve the Nusselt number compared to the pure EG. The highest Nusselt number is obtained for $\mathrm{Al}_{2} \mathrm{O}_{3}$-EG and followed by Nusselt number of CuO-EG. This is because of high value of thermal heat capacity of $\mathrm{Al}_{2} \mathrm{O}_{3}$-EG. Due to the fact, the existence of nanoparticle in the EG leads to increase the convective heat transfer performance. In addition, it is found that the Nusselt number is directly proportional to Reynolds number.

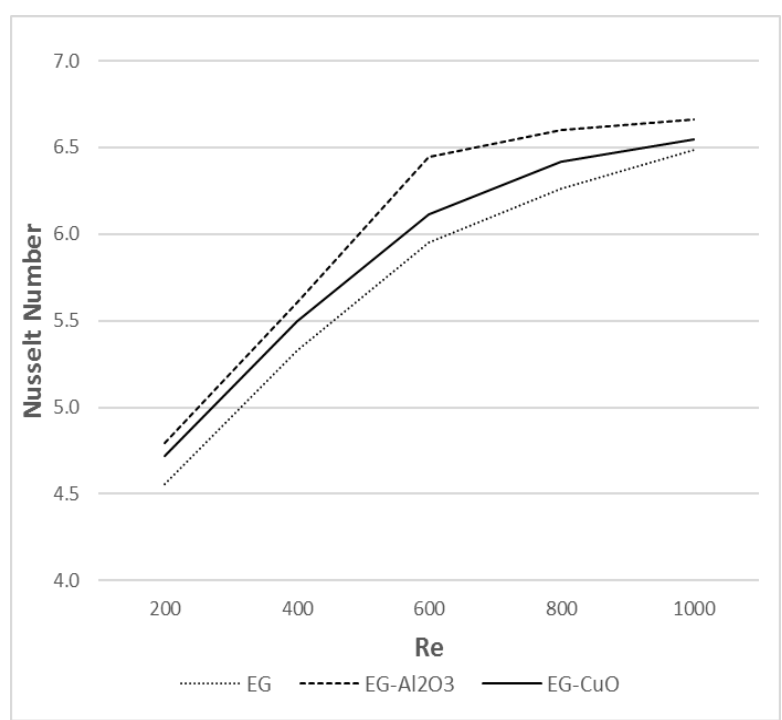

Fig. 7: Nusselt number for EG and various nanofluids

\subsection{Heat Transfer Rate}

Fig. 8 illustrated the heat transfer rate inside the LCP with the variation of Reynolds number. It is found that the heat transfer rate is directly proportional to Reynolds number. Furthermore, the
$\mathrm{Al}_{2} \mathrm{O}_{3}$-EG has the highest ability to dissipate heat followed by CuO-EG and pure EG, respectively. The LCP utilizing $\mathrm{Al}_{2} \mathrm{O}_{3}$-EG at a Reynolds number of 1200 was able to dissipate heat at the highest value of about 1082 while the LCP utilizing pure ethylene glycol was able to dissipate the lowest value of $552 \mathrm{~W}$ at a Reynolds number of 200 .

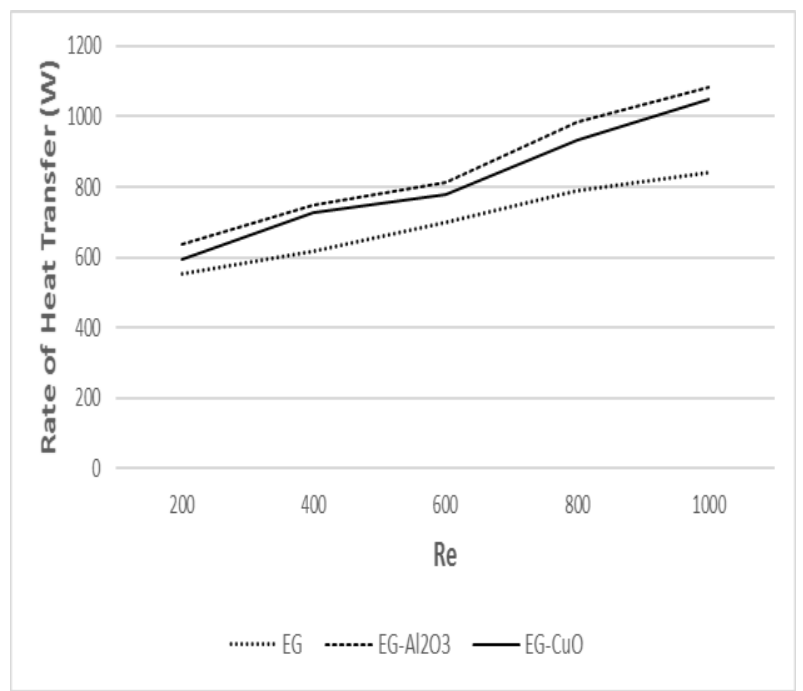

Fig. 8: Heat transfer rate for EG and various nanofluids

\subsection{Pressure Drop}

The pressure drop creates a significant effect over the heat transfer. This is because the pressure drop caused the interaction between fluid and the LCP to enhancing the heat transfer performance. Fig. 9 shows the pressure drop at inlet and outlet of the LCP. It is observed the pressure drop is getting high when increase Reynolds number. This is because the flow rate is getting intense as the Reynolds number increase hence it caused additional skin friction throughout the LCP. It also observed that the pressure drop for $\mathrm{Al}_{2} \mathrm{O}_{3}$-EG and $\mathrm{CuO}-\mathrm{EG}$ are higher compared to pure $\mathrm{EG}$ due to its higher viscosity of the nanofluids. Pressure drop happens because of collisions between the nanoparticle with the LCP.

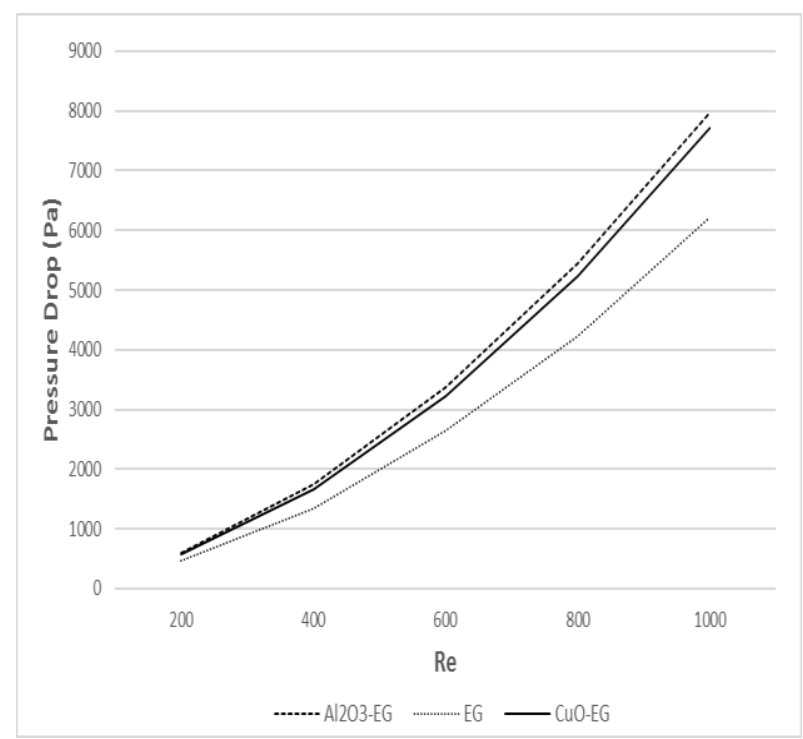

Fig. 9: Pressure drop for EG and various nanofluids

\subsection{Friction Factor}

The effect of mixing nanoparticles in EG on the friction factor is shown in Fig. 10. The result shows that as the Reynolds number increase the friction factor is decreases. As mentioned before this is due to frictional loss is high when the flow rate of the fluid is 
higher. The result also revealed that the friction factor for $\mathrm{Al}_{2} \mathrm{O}_{3^{-}}$ EG and CuO-EG significantly higher compared to pure EG. This is due to fact that the presence of nanoparticle in EG could slightly increase the friction factor along the LCP.

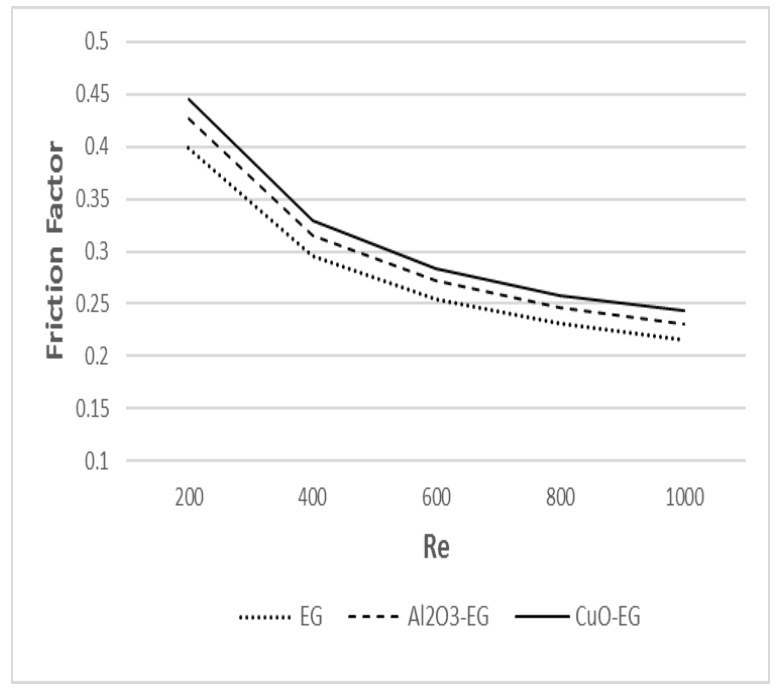

Fig. 10: Friction factor for EG and various nanofluids

\section{Conclusion}

The numerical study of LCP for battery thermal management system using nanofluids are reported in this current study. The influence of using two types of nanofluids which are EG- $\mathrm{Al}_{2} \mathrm{O}_{3}$ and $\mathrm{EG}-\mathrm{CuO}$ on the thermal performance and fluid flow is examined. As conclusion,

- $\mathrm{Al}_{2} \mathrm{O}_{3}$-EG has the lowest surface temperature and the Nusselt number. Whereas, pure EG has the highest surface temperature and the lowest Nusselt number.

- Existence of nanoparticles significantly increases the Nusselt number compared to the EG. The highest Nusselt number attained by using $\mathrm{Al}_{2} \mathrm{O}_{3}$-EG while the lowest rate of Nusselt number is occurred using pure EG.

- Pressure drop and friction factor are slightly higher for $\mathrm{Al}_{2} \mathrm{O}_{3}$-EG and CuO-EG compared to pure EG.

\section{References}

[1] Pesaran A. a, Vlahinos A. \& Burch S. D. (1997), Thermal Performance of EV and HEV Battery Modules and Packs. Centre for Transportation Technologies and Systems, National Renewable Energy Laboratory.

[2] Kim G. H., Pesaran A. (2003), 22nd International Battery, Hybrid abd Fuel Cell Electric Vehicle Conference and Exhibition, Yokohama, Japan.

[3] Tao D., Guodong Z., Yan R. (2018), Study on thermal management of rectangular Li-ion battery with serpentine-channel cold plate, International Journal Heat Mass Transfer 125, 143 - 152.

[4] Panchal S., Khasow R., Dincer I., Agelin-Chaab M., Fraser R., \& Fowler M. (2017), Thermal design and simulation of minichannel cold plate for water cooled large sized prismatic lithium-ion battery. Applied Thermal Engineering, 122, 80-90.

[5] Huo Y., Rao Z., Liu X., Zhao J. (1025), Investigation of power battery thermal management by using minichannel cold plate, Energy Conversion Management 89, 387-395.

[6] HuO Y, Rao Z, (2015), The numerical investigation of nanofluid based cylinder battery thermal management using lattice Boltzmann method, International Journal Heat Mass Transfer 91, 374 - 384.

[7] Lee S., Choi S.U.S., Li S., Eastman J.A. (1999), Measuring thermal conductivity of fluids contining oxide nanoparticles, Journal of Heat Transfer 121, 280-289.

[8] Maxwell J. C., A treatise on electricity and magnetism (1873), Clarendon Press, Oxford, UK.
[9] Ganapathy H., Shooshtari A., Choo K., Dessiatoun S., Alshehhi M., Ohadi M. (2013), Volume of fluid-based numerical modelling of condensation heat transfer and fluid flow characteristics in microchannels, International Journal Heat Mass Transfer 65, 62 - 72.

[10] Dede Ercan M., Liu Y. (2013), Experimental and numerical investigation of multi-pass branching microchannel heat sink with $\mathrm{Al}_{2} \mathrm{O}_{3}$ /water nanofluid, Applied Thermal Engineering 55, $51-60$.

[11] Sakanova A., Keian C. C., Zhoa J. (2015), Performance improvements of the micro-channel heat sink using wavy channel and nanofluids, International Journal Heat Mass Transfer 89, 59 74.

[12] Fan Y., Lee P. S., Jin L. W., Chua B. W. (2013), A simulation and experimental study of fluid flow and heat transfer on cylindrical oblique-finned heat sink, International Journal Heat Mass Transfer $61,62-72$.

[13] Mohd Rashdan A., Rozli Z., Shahrir A. (2015), Minichannel LCP for EV battery cooling: effect of fin spacing, International Journal of Mechanical \& Mechatronics Engineering, 15(4), 68-73. 